\title{
Reflex Control of Heart Rate in Normal Subjects in Relation to Age: A Data Base for Cardiac Vagal Neuropathy
}

\author{
W. Wieling, J. F. M. van Brederode, L. G. de Rijk, C. Borst and A. J. Dunning \\ Department of Medicine, Academic Medical Centre, and Department of Physiology, University of Amsterdam, \\ Amsterdam, The Netherlands
}

\begin{abstract}
Summary. We examined the heart rate changes induced by forced breathing and by standing up in 133 healthy subjects in the age range $10-65$ years in order to establish a data base for studies on parasympathetic heart rate control in autonomic neuropathy. Test results declined with age. Log-transformation was used to define the lower limit of normal $\left(\mathrm{P}_{0.10}\right)$ and an uncertainty range (values between $\mathrm{P}_{0.10}$ and $\mathrm{P}_{0.025}$ ). The lower limit of normal decreased from 22 to 11 beats/ min for forced breathing and from 26 to 16 beats $/ \mathrm{min}$ for standing up, with age increasing from 10 to 65 years. No subject scored below and only two subjects scored in or below the uncertainty range for both tests. Lack of correlation between both tests $(r=0.17)$ documents the different afferent mechanisms of the reflex heart rate changes. In combination these two tests form a simple and reliable bedside method to establish cardiac vagal neuropathy.
\end{abstract}

Key words: Diabetic autonomic neuropathy, vagal heart rate control, forced breathing, orthostatic reflexes.

Impaired vagal control of heart rate (HR) has been described in a variety of diseases, such as diabetes mellitus [1-3], uraemia [4] and rheumatoid arthritis [5]. In patients with diabetes mellitus, cardiac vagal dysfunction is most often detected in longstanding disease, but damage to the autonomic nervous system may even be present at diagnosis [6]. Abnormal autonomic cardiac function is prognostically important because it may be associated with a high mortality [7]. Instantaneous HR changes with forced breathing $[1-3,6,8-10]$ and after the transition from lying to standing $[7,8,10-12]$ are used as simple bedside tests to assess vagal $\mathrm{HR}$ control. In order to establish a data base for delineating abnormal vagal HR control from normal, we compared instantaneous HR changes with forced breathing and after standing up in 133 healthy volunteers in the age range $10-65$ years.

\section{Subjects and Methods}

Normal subjects consisted of medical students, hospital personnel and community volunteers. No medication other than oral contraceptives was used. Subjects were grouped according to age: 10-29 years $(n=64), 30-49$ years $(n=48), 50-65$ years $(n=21)$. Values for resting HR, blood pressure, weight and height are given in Table 1. Subjects were examined in the morning $(70 \%)$ or in the afternoon $(30 \%)$, at least $1 \mathrm{~h}$ after the last meal. They were requested to abstain from coffee and cigarettes on the day of the experiment. The instantaneous HR (beats/min) was determined by a cardiotachometer and monitored on a pen recorder (Servogor RE 511). The subjects rested in a supine position for at least $5 \mathrm{~min}$ before the measurements were started. The resting HR was taken as the mean value over a 30 -s period preceding the tests.

\section{Forced Respiratory Sinus Arrhythmia}

The subject was instructed to perform six consecutive maximal inspirations in the supine position at a rate of 6 breaths/min $[1-3,6$, 8]. From the pen recording we measured the mean difference between the maximum and minimum instantaneous HR during each of six consecutive cycles of forced inspiration and expiration: the I-E difference (beats/min) $[1-3,6,8]$.

\section{Standing Up from the Supine Position in 3-5s}

A marker connected to the pen recorder was used to identify the moment the subject began to stand up (time $t=0$ in RR-interval number $\mathrm{RR}_{0}$ ). A correction of $1 \mathrm{~s}$ was made to allow for the reaction time of the subject and the fact the cardiotachometer lagged one cardiac cycle. The following measurements were made:

(a) $\triangle \mathrm{HR}_{\operatorname{mix}}$ (beats/min), $\mathrm{T}_{\max }$ (s) and the number of the corresponding shortest $R R$-interval $\mathrm{RR}_{\min }[8,12,13]$

(b) $\triangle H R_{\min }, T_{\min }$ and the number of the corresponding longest $R R$ interval $R_{R_{\text {max }}}[8,12,13]$

For comparison with other studies $[8,12,13]$ we also determined the $R_{30} / R_{15}$ ratio and the $R_{R_{\max }} / R_{\text {min }}$ ratio. Blood pressure was measured at rest and after $1 \mathrm{~min}$ in the erect posture. 
Table 1. Physical characteristics of male and female subjects in the three age groups

\begin{tabular}{|c|c|c|c|c|c|c|}
\hline \multirow{3}{*}{$\begin{array}{l}\text { Age (years) } \\
\text { Sex } \\
\text { Number of subjects }\end{array}$} & \multicolumn{2}{|l|}{$10-29$} & \multicolumn{2}{|l|}{$30-49$} & \multicolumn{2}{|l|}{$50-65$} \\
\hline & M & $\mathrm{F}$ & $\mathbf{M}$ & $\mathrm{F}$ & $\mathrm{M}$ & $\mathrm{F}$ \\
\hline & 40 & 24 & 26 & 22 & 9 & 12 \\
\hline Height $(\mathrm{cm})$ & $176 \pm 12$ & $168 \pm 8$ & $179 \pm 8$ & $168 \pm 7$ & $178 \pm 6$ & $170 \pm 6$ \\
\hline Weight (kg) & $66 \pm 12$ & $60 \pm 7$ & $74 \pm 10$ & $62 \pm 11$ & $77 \pm 3$ & $63 \pm 4$ \\
\hline Resting heart rate (beats/min) & $70 \pm 12$ & $73 \pm 13$ & $65 \pm 10$ & $67 \pm 9$ & $67 \pm 9$ & $67 \pm 13$ \\
\hline Systolic blood pressure (mmHg) & $123 \pm 11$ & $120 \pm 9$ & $123 \pm 12$ & $114 \pm 10$ & $127 \pm 19$ & $135 \pm 16$ \\
\hline Diastolic blood pressure $(\mathrm{mmHg})$ & $74 \pm 4$ & $75 \pm 6$ & $76 \pm 6$ & $72 \pm 6$ & $80 \pm 9$ & $80 \pm 7$ \\
\hline
\end{tabular}

Results expressed as mean $\pm \mathrm{SD}$

Table 2. RR-interval changes in the first $30 \mathrm{~s}$ after standing up

\begin{tabular}{llll}
\hline $\begin{array}{l}\text { Age (years) } \\
\text { Number of subjects }\end{array}$ & $\begin{array}{l}10-29 \\
n=64\end{array}$ & $\begin{array}{l}30-49 \\
n=48\end{array}$ & $\begin{array}{l}50-65 \\
n=21\end{array}$ \\
\hline $\mathrm{T}_{\max }(\mathrm{s})$ & $12.0 \pm 2.8$ & $11.0 \pm 2.8$ & $12.0 \pm 3.4$ \\
$\mathrm{~T}_{\min }(\mathrm{s})$ & $21.2 \pm 4.0$ & $21.3 \pm 3.4$ & $23.5 \pm 3.5$ \\
$\mathrm{RR}_{\max }$ & $17 \pm 5$ & $15 \pm 4$ & $15 \pm 4$ \\
(interval number) & $31 \pm 7$ & $29 \pm 4$ & $30 \pm 5$ \\
$\mathrm{RR}_{\min }$ & & & \\
(interval number) & & & \\
$\mathrm{RR}_{30}$ & $1.27 \pm 0.20$ & $1.30 \pm 0.16$ & $1.17 \pm 0.12$ \\
$\mathrm{RR}_{15}$ & & & \\
$\mathrm{RR}_{\max }$ & $1.49 \pm 0.21$ & $1.44 \pm 0.17$ & $1.31 \pm 0.14$ \\
$\mathrm{RR}_{\min }$ & & & \\
\hline
\end{tabular}

Results expressed as mean $\pm \mathrm{SD}$

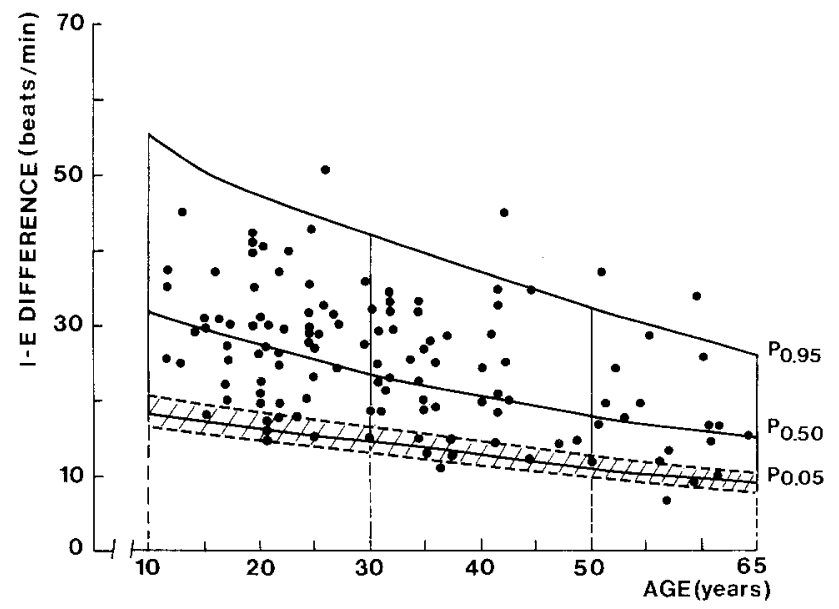

Fig. 1. Forced respiratory sinus arrhythmia (I-E difference) in relation to age. The regression line $\left(\mathrm{P}_{0.50}\right)$ and the $90 \%$ confidence limits (solid lines) were calculated from log-transformed values (see Methods). The hatched area indicates the uncertainty range; values below it are considered abnormally small, values above it are considered normal

\section{Statistical Analysis}

Test results were log-transformed because the data from each age group gave positively skewed distributions [14]. The log-normal data were fitted to the linear regression model $\log \hat{\mathrm{Y}}=\mathrm{a}+\mathrm{bX}(\hat{\mathrm{Y}}$ stands for test score, $\mathrm{X}$ for age). We calculated the $90 \%$ confidence limits for individual observations [14]. In order to establish a range of values from probably normal to probably abnormal - an uncertainty range - we also calculated the lower one-sided $90 \%$ and $97.5 \%$ confidence limits $\left(\mathrm{P}_{0.10}\right.$ and $\left.\mathrm{P}_{0.025}\right)$. The regression coefficient (b) was tested for deviation from zero. Differences between group means were tested using Student's ' $t$ ' test. The regression equation and the confidence limits were transformed back into normal scale. Correlation was calculated using Pearson's product moment correlation $(r)$. A $p<0.05$ was considered to indicate a significant difference.

\section{Results}

No influence of sex was found. Test results in the morning and afternoon did not differ significantly. Consequently all results were pooled.

\section{Forced Respiratory Sinus Arrhythmia}

The I-E difference ranged from 7 to 51 beats/min and declined with age (Fig. 1). The regression of the I-E difference with age is described by the equation log I-E difference $=1.5732-0.0060 \times$ age. The regression coefficient was significantly different from 0 $(p<0.001)$. The median I-E difference decreased from 33 to 15 with age increasing from 10 to 65 years. The lower limit of the $90 \%$ confidence interval $\left(\mathrm{P}_{0.05}\right)$ decreased from 19 at the age of 10 years to 9 at the age of 65 years. The uncertainty range $\left(\mathrm{P}_{0.025}\right.$ to $\mathrm{P}_{0.10} ;$ Fig. 1 , hatched area) shifted from 17-21 to 8-10. Two subjects scored below and 18 subjects scored within the uncertainty range. Correlation between I-E difference and resting HR was very poor $(r=0.31)$.

\section{Immediate Heart Rate Changes After Standing Up}

Orthostatic hypotension (systolic pressure fall $\geqslant 30 \mathrm{mmHg}$ ) was not observed. The time course of instantaneous HR changes showed a very characteristic response: an abrupt $\mathrm{HR}$ rise starting after $\leqslant 1 \mathrm{~s}$, a peak around $t=12 \mathrm{~s}$ and a trough around $t=22 \mathrm{~s}$ (Table 2$)$. HR continued to increase very little $(<5$ 
beats/min) in only 11 subjects after $15 \mathrm{~s}$ of standing up. For practical purposes the highest HR in the first $15 \mathrm{~s}$ was used as a measure for the initial peak HR rise to standing.

The $\triangle H R_{\max }$ ranged from 14 to 47 beats $/ \mathrm{min}$ and declined with age (Fig. 2). The regression of $\triangle H R_{\max }$ with age is described by the equation log $\Delta \mathrm{HR}_{\max }=$ $1.5864-0.0039 \times$ age. The regression coefficient was significantly different from $0(p<0.001)$.

The median $\triangle \mathrm{HR}_{\max }$ decreased from 35 to 22 , $\mathrm{P}_{0.05}$ from 22 to 13 and the uncertainty range (Fig.2, hatched area) shifted from $20-25$ to $12-15$ with age increasing from 10 to 65 years. No subject scored below and 17 subjects scored within the uncertainty range. The correlation between $\triangle H^{\prime} R_{\max }$ and resting $H R$ was very poor $(r=0.23)$. On average $\Delta \mathrm{HR}_{\max }$ was reached around $R_{15}$ and $\Delta \mathrm{HR}_{\min }$ around $R R_{30}$. However, since there were considerable individual differences, the $R R_{30} / R_{15}$ ratio underestimated the $\mathrm{RR}_{\max } / \mathrm{RR}_{\min }$ ratio (Table 2).

The $R_{\text {max }} / R_{\text {min }}$ ratio ranged from 1.08 to 1.98 and declined with age. The regression of the $R R_{\max } /$ $R R_{\min }$ ratio with age is dercribed by the equation log $\mathrm{RR}_{\max } / \mathrm{RR}_{\min }=0.2009-0.0014 \times$ age. The regression coefficient was significantly different from 0 $(p<0.001)$. The median $\mathrm{RR}_{\max } / \mathrm{RR}_{\min }$ decreased from 1.54 to $1.29, \mathrm{P}_{0.05}$ from 1.25 to 1.05 and the uncertainty range shifted from $1.31-1.20$ to $1.09-1.01$ with age increasing from 10 to 65 years. Three subjects scored below and 8 subjects scored within the uncertainty range. The correlation between the $R R_{\max } /$ $\mathrm{RR}_{\min }$ ratio and resting $\mathrm{HR}$ was very poor $(r=0.19)$.

\section{Correlation Between HR Changes After Forced Breathing and Standing $U p$}

The correlation between I-E difference and $\triangle H R_{\max }$ $(r=0.17)$ and $\mathrm{I}-\mathrm{E}$ difference and $\mathrm{RR}_{\max } / \mathrm{RR}_{\min }$ ratio $(r=0.14)$ was very poor. Two out of 133 subjects scored in or below the uncertainty range for the I-E difference and $\triangle H R_{\max }$, and only one in the uncertainty range for the I-E difference and the $R R_{\max } /$ $R R_{\min }$ ratio. No subject scored below the uncertainty range for both tests.

\section{Discussion}

Instantaneous HR changes induced by deep breathing and standing up are commonly used to assess vagal damage in diabetic autonomic neuropathy. The principal results of the present investigation in a large number of healthy subjects are: test results showed a huge scatter (for instance largest I-E difference seven times smallest difference) and skewed distributions. Analysis of test results after log-transformation enabled defining an 'uncertainty range' based on parametric statistics. Only two subjects scored within or

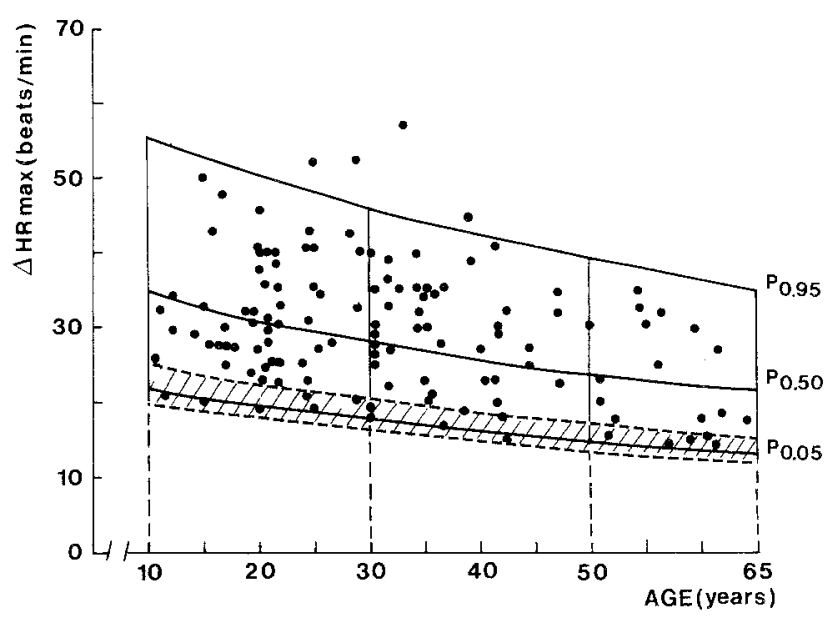

Fig. 2. Immediate $H R$ increase after standing up $\left(\triangle H R_{\text {max }}\right)$ in relation to age. The hatched area indicates the uncertainty range (see legend to Fig. 1)

Table 3. Lowest normal value for I-E difference, $\triangle H R_{\max }$ and $R R_{\max } / R R_{\min }$ ratio

\begin{tabular}{llllll}
\hline Author & No. of subjects & $\begin{array}{l}\text { Age } \\
\text { (years) }\end{array}$ & $\begin{array}{l}\text { I-E difference } \\
\text { (beats/min) }\end{array}$ & $\begin{array}{l}\Delta \mathrm{HR}_{\max } \\
\text { (beats/min) }\end{array}$ & $\begin{array}{l}\mathrm{RR}_{\max } / \mathrm{RR}_{\min } \\
\text { ratio }\end{array}$ \\
\hline This study & 64 & $10-29$ & $20(15-19)$ & $24(19-23)$ & $1.28(1.17-1.27)^{\mathrm{a}}$ \\
& 48 & $30-49$ & $15(11-14)$ & $20(16-19)$ & $1.20(1.09-1.19)$ \\
& 21 & $50-65$ & $12(9-11)$ & $17(13-16)$ & $1.13(1.03-1.12)$ \\
Mackay et al. [8] & 54 & $20-49$ & $13(9-12)$ & $16(12-15)$ & $1.12(1.04-1.11)$ \\
Wheeler and Watkins [1] & 17 & $20-50$ & 11 & & \\
Page and Watkins [2] & 39 & $<50$ & 16 & & \\
Hilsted and Jensen [9] & 10 & $20-40$ & 16 & & \\
Dyrberg et al. [10] & 28 & $30-48$ & 9 & & \\
\hline
\end{tabular}

Values in parentheses are the boundary values of the uncertainty range in the present study and the borderline values reported by other authors. The uncertainty range is calculated for the midpoint of the three age groups

a After log-transformed data 
below the uncertainty range in both tests. The HR changes evoked by forced breathing and by standing up declined with age $[2,8]$.

The present results are in general agreement with previous studies [1-3,8-10], but comparison of tests scores considered to be the lower limit of normal by different authors (Table 3 ) shows that the more rigorous analysis in the present study improved the criteria for delineating abnormal from normal in individual testing of reflex vagal heart rate control. The very poor correlation between the HR changes with forced breathing and after standing up emphasizes that different afferent mechanisms are involved [3]. If we assume that these are entirely independent, there is a $1 \%$ chance that a healthy individual would score within or below the uncertainty range in both tests, and a $0.06 \%$ chance that scores below the uncertainty range would be obtained. Thus, in combination these two tests are eminently suited for bed-side screening of cardiac vagal neuropathy. No subjects had orthostatic hypotension after $1 \mathrm{~min}$ of standing. The immediate HR response to standing showed a striking pattern in time: the peak HR rise was found after about $12 \mathrm{~s}$, the subsequent relative minimum after about $22 \mathrm{~s}$ (Table 2 ), values almost identical to those reported in previous studies [12,15,16]. Ewing et al. [12] characterized the HR response by calculating the ratio between the 30th and 15th RR-interval. Although the maximal HR was reached near $R_{15}$ and minimal $H R$ near $R_{30}$ (Table 2), there were considerable individual differences and the $R R_{30} / R_{15}$ ratio was lower than the $\mathrm{RR}_{\text {max }} / \mathrm{RR}_{\min }$ ratio (Table 2). Thus, the $\mathrm{RR}_{\max } /$ $\mathrm{RR}_{\text {min }}$ ratio is superior [5, 8] to the $\mathrm{RR}_{30} / \mathrm{RR}_{15}$ ratio [10, 17] for testing abnormal vagal $H R$ control in diabetic patients.

Acknowledgements. We would like to express our appreciation to J.M. Karemaker, Department of Physiology for critical suggestions, and to J.Oosting and A. A. M. Hart, Department of Medical Physics for statistical advice.

\section{References}

1. Wheeler T, Watkins PJ (1973) Cardiac denervation in diabetes. Br Med J 4: 584-586

2. Page MMcB, Watkins PJ (1977) The heart in diabetes: auto- nomic neuropathy and cardiomyopathy. Clin Endocrinol Metab 6: 377-388

3. Bennett T, Faquhar IK, Hosking DJ, Hampton JR (1978) Assessment of methods for estimating autonomic nervous control of the heart in patients with diabetes mellitus. Diabetes 27: $1167-1174$

4. Naik RB, Mathias CJ, Wilson CA, Reid JL, Warren DJ (1981) Cardiovascular and autonomic reflexes in haemodialysis patients. Clin Sci 60: 165 170

5. Edmonds ME, Jones TC, Saunders WA, Sturrock RD (1979) Autonomic neuropathy in rheumatoid arthritis. Br Med J 2: 173-175

6. Watkins PJ, Mackay JD (1979) Cardiac denervation in diabetic neuropathy. Ann Intern Med 92: 304-307

7. Ewing DJ, Campbell IW, Clarke BF (1979) Assessment of cardiovascular effects in diabetic autonomic neuropathy and prognostic implications. Ann Intern Med 92: 308-311

8. Mackay JD, Page MMcB, Cambridge J, Watkins PJ (1980) Diabetic autonomic neuropathy: the diagnostic value of heart rate monitoring. Diabetologia 18: 471-478

9. Hilsted J, Jensen SB (1979) A simple test for autonomic neuropathy in juvenile diabetics. Acta Med Scand 205:385-387

10. Dyrberg T, Bern J, Christiansen JS, Hilsted J, Nerup J (1981) Prevalence of diabetic autonomic neuropathy measured by simple bedside tests. Diabetologia 20: 190-194

11. Clarke BF, Ewing DJ, Campbell IW (1979) Diabetic autonomic neuropathy. Diabetologia 17: 195-212

12. Ewing DJ, Campbell JW, Murray A, Neilson JMM, Clarke BF (1978) Immediate heart rate response to standing: simple test for autonomic neuropathy in diabetes. Br Med $\mathrm{J} 1: 145-147$

13. Ewing DJ, Hume L, Campbell JW, Murray A, Neilson JMM, Clarke BF (1980) Autonomic mechanisms in the initial heart rate response to standing. J Appl Physiol 49:809-814

14. Armitage P (1971) Statistical methods in medical research. Blackwell Scientific Publications, Oxford, pp 163-166, 352

15. Drischel $H$ von, Fanter H, Gürtler $H$, Labitzke H, Priegnitz $H$ (1963) Das Verhalten der Herzfrequenz gesunder Menschen beim Übergang vom Liegen zum Stehen. Archiv für Kreislaufforschung 40: 135-167

16. White NJ (1980) Heart rate changes on standing in elderly patients with orthostatic hypotension. Clin Sci 58:411-413

17. Ewing DJ, Campbell JW, Clarke BF (1978) Heart rate response to standing as a test for autonomic neuropathy. Br Med J 1: 1700

Received: 19 May 1981

and in revised form: 4 August 1981

Wouter Wieling, M.D.

Department of Medicine

Academic Medical Centre

Meibergdreef 9

NL-1 105 AZ Amsterdam The Netherlands 